\title{
Determination of Phthalates in Polymer Materials - Comparison of GC/MS and GC/ECD Methods
}

\author{
Katarzyna Jaworek, Marianna Czaplicka \\ Institute of Non - ferrous Metals, Poland
}

\begin{abstract}
The paper presents two methods for determination of phthalates in polymer materials. The methods compared were gas chromatography combined with the mass spectrometry (GC/MS) and gas chromatography with electron capture detector (GC/ECD). The GC/ECD technique was chosen for this comparison, because the ECD detector was one of few capable of detecting phthalates. In both cases the same procedure of sample preparation with ultrasonic extraction was applied. Overall recoveries were 76-100\% with relative of standard deviation (R.S.D.) values in the range 0.6-19\%. The values of limit of detection (LOD) for GC/MS method ranged from $3.46 \mu \mathrm{g} \mathrm{mL}^{-1}$ to $10.10 \mu \mathrm{g}$ $\mathrm{mL}^{-1}$, depending on the determined phthalate, while in case of the GC/ECD method they were in the range from $2.97 \mu \mathrm{g} \mathrm{mL} \mathrm{m}^{-1}$ to $4.29 \mu \mathrm{g} \mathrm{mL} \mathrm{m}^{-1}$. The methods were applied for determination of: dimethyl phthalate, diethyl phthalate, di-n-butyl phthalate, benzyl butyl phthalate, bis(2-ethylhexyl) phthalate, diisononyl phthalate, diisoocyl phthalate in polymer material. The seventeen kinds of samples were analyzed. Most of the materials selected for the analyses were made from polyethylene (PE), polyvinyl chloride (PVC) and polystyrene (PS).
\end{abstract}

Keywords: Gas chromatography, mass spectrometry, electron capture detector, phthalates, polymer material.

\section{Introduction}

Each year tons of phthalates are produced in the world in various manufacturing processes. Phthalic acid esters (PAEs) are additives in plastics, mainly in polyvinylchroride (PVC) products. These compounds are excellent plasticizers because of their stability, flowability, low volatility and high molecular weight. Due to their widespread use, relatively large amounts of those compounds are released into the environment. It has been proven that phthalates are impermanently associated with the polymer matrix and can easily migrate from the plastic to the external environment, they may be leached into foods and beverages from the packing material, resulting in harmful effects on the human body and the environment. The phthalates have attracted great public attention because of the suspicion of their carcinogenic and estrogenic properties ${ }^{[1]}$. Because of the health concern, the European Commission began restricting phthalates in $2000^{[2]}$ and U.S. government passed the Consumer Products Safety Improvement Act (CPSIA) in August of 2008.

Some phthalates are included in the priority lists of pollutants in several countries. US Environmental Protection Agency (EPA) has established the maximum admissible concentration in water of $6 \mathrm{mg} \mathrm{L}^{-1}$ for the di(2-ethylhexyl)phthalate $(\mathrm{DEPH})^{[3]}$. The regulations in Europe specify limits for six phthalates: di(2-ethylhexyl) phthalate, dibutyl phthalate, benzylbutyl phthalate, diisononyl phthalate, diisodecyl phthalate and di-noctyl phthalate at the level less than $0,1 \%$ in all toys and articles designed so that they can be put in a child's mouth $^{[4]}$. As a result of those regulations, industries have to monitor the presence and amount of those specific compounds. The identification and quantification of phthalates requires an analytical technique which can separate each phthalate from other additives and from the plastic matrix itself. In recent years, several methods for the determination of phthalates by gas chromatography $(\mathrm{GC})^{[1,5-10]}$ and by high performance liquid chromatography (HPLC) ${ }^{[11-20]}$ were described. Different methods of sample preparation and extraction have been used, such as liquid - liquid extraction $(\mathrm{LLE})^{[7,21]}$, solid phase extraction $(\mathrm{SPE})^{[1,6,11,12,16,17,21]}$, solid phase microextraction (SPME) ${ }^{[8,20,22,23]}$, supercritical fluid extraction ${ }^{[21]}$, microwave extraction ${ }^{[13,21]}$, Soxhlet extraction $^{[10,21,24]}$ and ultrasonic extraction ${ }^{[5,21,25]}$.

In this paper, the studies of gas chromatography in combination with mass spectrometry detector (MS) and electron capture detector (ECD) for determination of seven kinds of phthalates, e.g. dimethyl phthalate (DMP), diethyl phthalate (DEP), dibutyl phthalate (DBP), benzylbutyl phthalate (BBP), di(2-ethylhexyl) phthalate (DEHP), diisononyl phthalate (DINP), diisooctyl phthalate (DIOP), in polymeric products for everyday use were developed. The methods were evaluated by investigating the accuracy and precision. Seventeen kinds of samples, including parts of a cable, a plug, and a garden hose were tested.

\section{Experimental}

\section{Chemicals and materials}

Methanol of HPLC isocratic grade was purchased from J.T. Baker Company (Deventer, Netherlands); methylene chloride, hexane and toluene were purchased from POCH (Gliwice, Poland). The standard mixture consisted of: dimethyl phthalate, diethyl phthalate, di-n-butyl phthalate, benzyl butyl phthalate, bis(2-

Corresponding author: Katarzyna Jaworek, Institute of Non - ferrous Metals, 5 Sowinskiego Str. 44-100 Gliwice, Poland, 
ethylhexyl) phthalate, all dissolved in methanol, each at a concentration of $500 \mu \mathrm{g} \mathrm{mL} \mathrm{m}^{-1}$ (EPA 506 Phthalate Esters Mix), diisononyl phthalate, diisoocyl phthalate and Amberlite XAD-2 were purchased from Supelco Company (Bellefonte, PA, USA). Silica gel 60 for column chromatography, was purchased from Merck (Merck KGaA, Germany).

\section{Apparatus and equipment}

The GC/MS analysis was performed on a Perkin Elmer Clarus 500 gas chromatograph equipped with a Clarus 500 mass detector (PerkinElmer, USA). Gas chromatographic analyses were also carried out using the Perkin Elmer Clarus 500 gas chromatograph equipped with an electron capture detector $\left({ }^{63} \mathrm{Ni} \mathrm{ECD}\right)$. Capillary columns Elite - 5MS ( 5\% diphenyl, 95\% dimethylpolysiloxane) of $30 \mathrm{~m}$ length $\times 0.25 \mathrm{~mm}$ ID with film thickness 0.25

$\mu \mathrm{m}$, (PerkinElmer, Shelton, USA) were employed for separation of analytes in both methods.

\section{Standards and spiked samples}

Standard mixture of five phthalates in methanol at concentration $500 \mu \mathrm{g} \mathrm{mL}{ }^{-1}$ was stored at $4^{\circ} \mathrm{C}$. Standards of diisononyl and diisooctyl phthalates were prepared in methanol at concentration of $784 \mu \mathrm{g} \mathrm{mL}{ }^{-1}$ and stored at $4^{\circ} \mathrm{C}$. Suitable working solutions with concentration in the range of $6.12-250 \mu \mathrm{g} \mathrm{mL} \mathrm{m}^{-1}$ were prepared as standards before the use for calibration curves.

\section{Sample collection}

For the purpose of this paper, seventeen kinds of polymer materials, like plastic parts of a plug, cables, a garden hose, containers, pipes and pellets, were analyzed. Most of the materials selected for the analyses were made from polyethylene (PE), polyvinyl chloride (PVC) and polystyrene (PS). Seven kinds of phthalates (DMP, DEP, DBP, BBP, DEHP, DIOP, DINP) were screened and determined by GC/MS and GC/ECD methods.

\section{Extraction}

The phthalates are removed from the polymer surface with a solvent in which they are soluble. In this case methylene chloride was chosen as the best solvent for the extraction of those compounds. The polymer samples were cut with scissors into pieces of less than $4 \mathrm{~mm}^{2}$, to improve extraction efficiency. Approximately $10 \mathrm{~g}$ of each grated sample was transferred to a glass conical flask and soaked in $75 \mathrm{~mL}$ of methylene chloride, followed by sonication for 1 hour. Due to the high efficiency of extraction, the extract contained substantial amounts of the monomers which are soluble in methylene chloride. The extract purification step by open liquid chromatography with the use of $\mathrm{SiO}_{2}$ was introduced ${ }^{[26]}$.

\section{Conditions of the analysis}

The column temperatures for gas chromatograph with a mass spectrometer and gas chromatograph with ECD detector were programmed to increase from 40 to $290^{\circ} \mathrm{C}$ at $20^{\circ} \mathrm{C} \mathrm{min}-1$ and from 290 to $310^{\circ} \mathrm{C}$ at $20^{\circ} \mathrm{C} \mathrm{min}^{-1}$ and held $9 \mathrm{~min}$; the temperature of an injector was $250^{\circ} \mathrm{C}$. In case of GC/MS, the temperature of ion source was $230^{\circ} \mathrm{C}$ and EI mass spectra were obtained at $70 \mathrm{eV}$. The temperature of ECD detector was $310^{\circ} \mathrm{C}$. An overview of the GC/MS and GC/ECD parameters was given in Table 1.

Qualitative analysis was performed on GC/MS chromatograph by comparing the retention times and the mass spectra registered for the compounds corresponding to the particular peaks in the chromatogram with the mass spectra found in reference libraries. The chromatogram of the standard mixture is presented in Figure 1. Also, qualitative analysis was performed on a GC/ECD chromatograph. Phthalates were identified by their retention times (Figure 2 ).

In the case of GC/MS, quantitative analysis was performed using selected ion monitoring method (SIM), choosing one or two ions typical for each compound (Table 2).

A direct injection calibration curve was generated based on the standard injections in a solvent solution. Detector signals, measured in arbitrary units (peak areas), were plotted versus the amount of analyte injected, expressed in mass units $(\mu \mathrm{g})$. Quantification of target compounds had to be done within the linearity range of the calibration curve, and in order to determine this range for the detector, several standard solutions have been prepared

Table 1. Gas chromatographic, mass spectrometric and electron capture detector parameters used for analysis of phthalates in selected polymer materials.

\begin{tabular}{lcc}
\hline \multicolumn{1}{c}{ Parameter } & GC/MS & GC/ECD \\
\hline Injector temperature $\left({ }^{\circ} \mathrm{C}\right)$ & & 250 \\
\hline Injection volume $(\mu \mathrm{L})$ & & 1,0 \\
\hline GC temperature program & & $40^{\circ} \mathrm{C}($ hold 3 min. $)$ \\
& & $290^{\circ} \mathrm{C}\left(20^{\circ} \mathrm{C}\right.$ min. $\left.{ }^{-1}\right)$ \\
& & $310^{\circ} \mathrm{C}\left(20^{\circ} \mathrm{C} \mathrm{min.} .^{-1}\right.$ hold 9 min. $)$ \\
\hline GC carrier gas: $\mathrm{He}\left(\mathrm{ml} \mathrm{min}^{-1}\right)$ & & 1,0 \\
\hline EI & 230 & \\
Ion source $\left({ }^{\circ} \mathrm{C}\right)$ & 150 & 310 \\
Quadrupole $\left({ }^{\circ} \mathrm{C}\right)$ & 70 & \\
Electron energy $(\mathrm{eV})$ & & \\
ECD detector temperature $\left({ }^{\circ} \mathrm{C}\right)$ & & \\
\hline
\end{tabular}




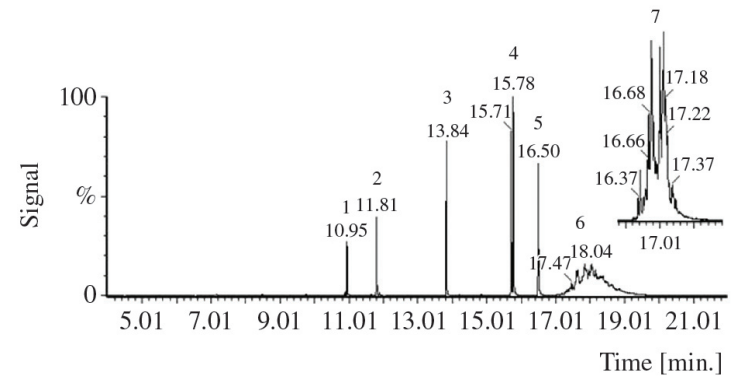

Figure 1. The chromatographic result of the GC/MS analysis of a phthalate standard at the concentration of $500 \mu \mathrm{g} \mathrm{mL}^{-1}$ obtained by full - scan mode; 1- DMP, 2 - DEP, 3- DBP, 4 - BBP, 5-DEHP, 6- DINP, 7- DIOP.

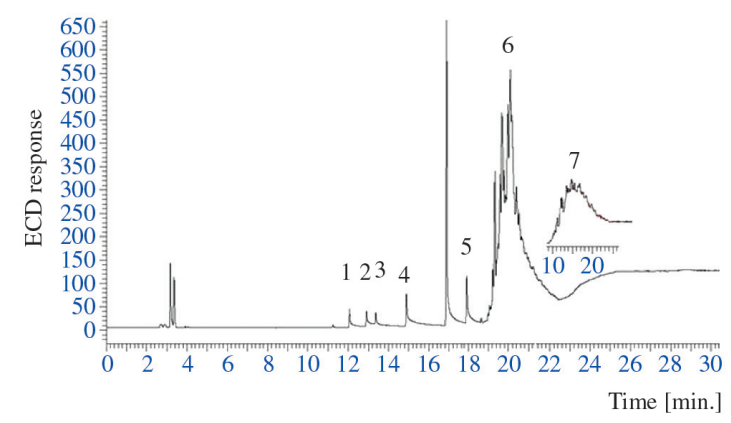

Figure 2. The chromatographic result of the GC/ECD analysis of a phthalate standard at the concentration of $500 \mu \mathrm{g} \mathrm{mL}-1$; DMP, 2 - DEP, 3- DBP, 4 - BBP, 5- DEHP, 6- DINP, 7-DIOP.

Table 2. Selected ions for each of the seven phthalates by GC/ MS studies $\mathrm{m} / \mathrm{z}$ values.

\begin{tabular}{ccc}
\hline & $\mathbf{m} / \mathbf{z}$ & $\begin{array}{c}\text { Retention } \\
\text { time }(\mathbf{m i n})\end{array}$ \\
\hline DMP & $77,92,135,163,194$ & 10.65 \\
DEP & $121,149,191,209$ & 11.52 \\
DBP & 104,149 & 13.84 \\
BBP & $91,132,149,206$ & 15.40 \\
DEHP & $113,149,167,279$ & 16.15 \\
DIOP & $71,113,149,167,279$ & 16.75 \\
DINP & $71,149,167,293$ & 18.05 \\
\hline
\end{tabular}

and injected at different concentrations. The calibration range for five phthalates (DMP, DEP, DBP, BBP, DEHP) was from 10 to $40 \mu \mathrm{g} \mathrm{mL} \mathrm{m}^{-1}$ for low concentrations and from 50 to $500 \mu \mathrm{g} \mathrm{mL}^{-1}$ for high concentrations, for DINP and DIOP one calibration range from 784 to $6,12 \mu \mathrm{g} \mathrm{mL}^{-1}$ was obtained. For each compound in both methods calibration curves were obtained by linear regression of the peak area against the concentration injected. As an example of a calibration curve, the curve of dimethyl phthalate at lower concentration for the GC/MS method is presented in Figure 3.

\section{Recovery determination}

No certified reference material for phthalate analysis exists. To determine the recovery of analytes, the reference materials were made. Amberlite XAD-2, which

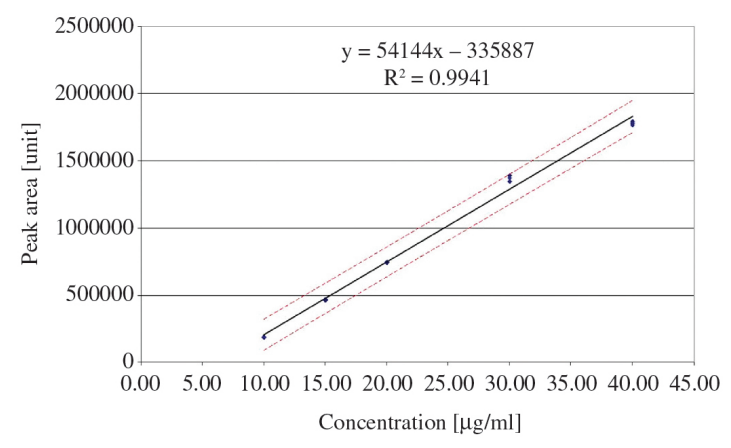

Figure 3. Calibration curve of dimethyl phthalate at range of concentration from 10 to $40 \mu \mathrm{g} \mathrm{mL}^{-1}$; the solid line - calibration curve, the dotted line - deviation of calibration curve.

is a hydrophobic crosslinked polystyrene copolymer resin, and plasticizer pellets made from PVC free from the target compound, were used as a templates for phthalates extraction optimization. A sample of Amberlite XAD-2 and plasticizer were extracted three times with methylene chloride and dried until the solvent was completely removed. The $10 \mathrm{~g}$ of dried samples were spiked with $50 \mu \mathrm{L}$ of a standard mixture containing DINP phthalate. In order to select the most efficient extractant/solvent for extraction of phthalates, the reference materials were extracted with methylene chloride, hexane and toluene. The obtained results are shown in Table 3.

\section{Extraction efficiency confirmation for real samples}

A five real samples of polymer material (plasticizer pellets), pre-prepared in accordance with the procedure described above, weighing $20 \mathrm{~g}$ were divided into two equal parts A and B. In samples A the phthalates were determined in according to the Extraction procedure. For some variations in this study, to improve real sample quantification accuracy, internal standard of DINP $\left(52.2 \mu \mathrm{g} \mathrm{g}^{-1}\right)$ phthalate has been added to B samples before extraction, to partially compensate for individual matrix or extraction effects. This should improve correlation between reported amount and real sample concentration. The results, comparing extraction recoveries from $\mathrm{A}$ and B samples, are shown in Table 4.

\section{Real samples}

Seventeen kinds of polymeric materials were tested. In order to determine phthalates in plastic products various items were bought randomly. The products that were used as samples included plastic parts of a plug, cables, a garden hose, containers, pipes and pellets. Most of the materials selected for the analysis were made from polyethylene, polystyrene and polyvinyl chloride. In accordance with the procedure outlined above, after cutting and homogenizing, the samples were extracted. The obtained extract was filtered, purified and analyzed.

\section{Results and Discussion}

The preliminary study of extraction efficiency of phthalates from polymeric materials has shown that the best recovery of DINP from the reference materials was 
obtained using methylene chloride. In case of this solvent DINP recovery from both reference materials were about $100 \%$ with R.S.D 2.7-3.3\%. For the other solvents, like hexane and toluene, the recovery reached a value below $70 \%$ for reference materials made from Amberlite XAD2 and plasticizer pellets (Table 3). Methylene chloride was chosen for the further analysis of real samples. To confirm extraction efficiency of phthalates from real polymer materials, the plasticizer pellet samples (B) with $\operatorname{DINP}\left(52.2 \mu \mathrm{g} \mathrm{g}^{-1}\right)$ as an internal standard, and plasticizer pellet samples (A) without internal standard were extracted in accordance with above described procedure. The almost $100 \%$ extraction efficiency of DINP phthalate was confirmed for the real polymer material (Table 4).

Table 3. Effects of solvents on extraction of phthalates in the prepared reference materials spiked with DINP $\left(78.4 \mu \mathrm{g} \mathrm{g}^{-1}\right)$ determined by GC/MS-SIM.

\begin{tabular}{|c|c|c|c|c|c|}
\hline \multirow[t]{2}{*}{ Isolation } & \multicolumn{2}{|c|}{ Reference } & \multirow{2}{*}{$\begin{array}{c}\text { DINP } \\
\text { (found } \mu \mathrm{g} \mathrm{g}^{-1} \text { ) }\end{array}$} & \multicolumn{2}{|c|}{ Average } \\
\hline & material & Solvent & & recovery $(\%)$ & R.S.D. (\%) \\
\hline \multirow{3}{*}{ Ultrasonication } & \multirow{3}{*}{$\begin{array}{c}\text { Amberlite } \\
\text { XAD-2 }\end{array}$} & Dichloromethane & 93.4 & 101.1 & 2.71 \\
\hline & & Hexane & 50.3 & 64.1 & 11.84 \\
\hline & & Toluene & 53.2 & 67.82 & 3.26 \\
\hline \multirow{3}{*}{ Ultrasonication } & \multirow{3}{*}{$\begin{array}{c}\text { Plasticizer } \\
\text { pellets }\end{array}$} & Dichloromethane & 77.6 & 99.7 & 3.32 \\
\hline & & Hexane & 46.3 & 62.3 & 15.61 \\
\hline & & Toluene & 51.4 & 65.6 & 4.12 \\
\hline
\end{tabular}

Table 4. Comparison of extraction recoveries from A samples (plasticizer pellets), and B samples with DINP $\left(52.2 \mu \mathrm{g} \mathrm{g}^{-1}\right)$ internal standard, determined by GC/MS-SIM.

\begin{tabular}{|c|c|c|c|c|}
\hline Isolation & Sample & Solvent & DINP (found $\mu \mathrm{g} \mathrm{g}^{-1}$ ) & R.S.D. (\%) \\
\hline \multirow{10}{*}{ Ultrasonication } & \multirow{5}{*}{ A } & \multirow{10}{*}{ Dichloromethane } & 74.6 & 3.57 \\
\hline & & & 74.3 & 2.98 \\
\hline & & & 74.9 & 3.14 \\
\hline & & & 74.7 & 3.64 \\
\hline & & & 74.5 & 3.28 \\
\hline & \multirow{5}{*}{ B } & & $126.3(52.2+74.1)$ & 3.32 \\
\hline & & & $126.7(52.2+74.5)$ & 3.84 \\
\hline & & & $126.4(52.2+74.2)$ & 3.71 \\
\hline & & & $127.1(52.2+74.9)$ & 3.56 \\
\hline & & & $126.8(52.2+74.6)$ & 3.19 \\
\hline
\end{tabular}

A- real polymer samples (plasticizer pellets). B - real polymer samples (plasticizer pellets) + DINP internal standard $\left(52.2 \mu \mathrm{g} \mathrm{g} \mathrm{g}^{-1}\right)$.

Table 5. Average recovery obtained by the extraction of phthalates from reference materials with methylene chloride ( R, \%).

\begin{tabular}{ccccc}
\hline \multirow{2}{*}{ Phthalates } & \multicolumn{2}{c}{ Amberlite XAD-2 } & \multicolumn{2}{c}{ Plasticizer pellets } \\
\cline { 2 - 5 } & Recovery [\%] & R.S.D [\%] & Recovery [\%] & R.S.D [\%] \\
\hline DMP & 98.2 & 18.9 & 96.7 & 20.1 \\
DEP & 100.0 & 7.9 & 99.3 & 10.5 \\
DnBP & 100.0 & 10.3 & 99.8 & 11.1 \\
BBP & 76.2 & 1.7 & 71.6 & 3.7 \\
DEHP & 100.0 & 1.3 & 99.1 & 2.4 \\
DIOP & 109.7 & 0.4 & 99.8 & 1.1 \\
DINP & 101.1 & 2.7 & 99.7 & 4.3 \\
\hline
\end{tabular}

Table 6. Regression coefficients for GC/MS and GC/ECD methods.

\begin{tabular}{|c|c|c|c|c|}
\hline \multirow{3}{*}{ Phthalate } & \multicolumn{2}{|c|}{ GC/MS } & \multicolumn{2}{|c|}{ GC/ECD } \\
\hline & $500-50 \mu \mathrm{g} \mathrm{mL}^{-1}$ & $40-10 \mu \mathrm{g} \mathrm{mL}^{-1}$ & $500-50 \mu \mathrm{g} \mathrm{mL}^{-1}$ & $40-10 \mu \mathrm{g} \mathrm{mL}^{-1}$ \\
\hline & $\mathbf{r}^{2}$ & $\mathbf{r}^{2}$ & $\mathbf{r}^{2}$ & $\mathbf{r}^{2}$ \\
\hline DMP & 0.999 & 0.994 & 0.999 & 0.991 \\
\hline DEP & 0.994 & 0.994 & 0.995 & 0.992 \\
\hline DBP & 0.988 & 0.996 & 0.986 & 0.996 \\
\hline BBP & 0.988 & 0.999 & 0.958 & 0.993 \\
\hline \multirow[t]{2}{*}{ DEHP } & 0.999 & 1.000 & 0.983 & 0.994 \\
\hline & \multicolumn{2}{|c|}{$784-12.3 \mu \mathrm{g} \mathrm{mL}^{-1}$} & \multicolumn{2}{|c|}{$784-6.12 \mu \mathrm{g} \mathrm{mL}^{-1}$} \\
\hline DIOP & \multicolumn{2}{|c|}{0.997} & \multicolumn{2}{|c|}{0.991} \\
\hline DINP & \multicolumn{2}{|c|}{0.992} & \multicolumn{2}{|c|}{0.993} \\
\hline
\end{tabular}




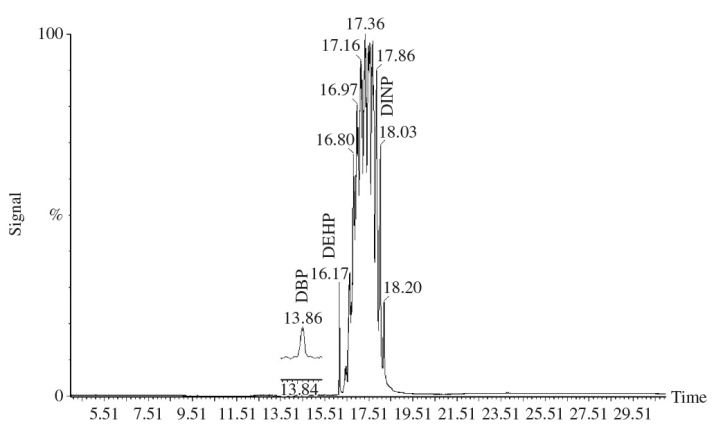

Figure 4. Chromatogram of plasticizer sample (GC/MS).
In samples A the average concentration of DINP was $74.6 \mu \mathrm{g} \mathrm{g}^{-1}$, with R.S.D in range from 2.98 to $3.64 \%$. The concentration of DINP internal standard added to B samples was $52.2 \mu \mathrm{g} \mathrm{g}^{-1}$, and $126.7 \mu \mathrm{g} \mathrm{g}^{-1}$ was an average determined concentration of DINP in those samples. These results shown that, also in case of the

B samples, average concentration of DINP phthalate was $74.5 \mu \mathrm{g} \mathrm{g}^{-1}$ and it confirmed almost $100 \%$ extraction efficiency for the real polymer samples. It was shown that recoveries for each compound were very high - near $100 \%$, only in the case of benzylbutyl phthalate it was equal to $76 \%$ (Table 5).

Application of the Elite-5MS column with GC/ MS and GC/ECD chromatographs enables a very
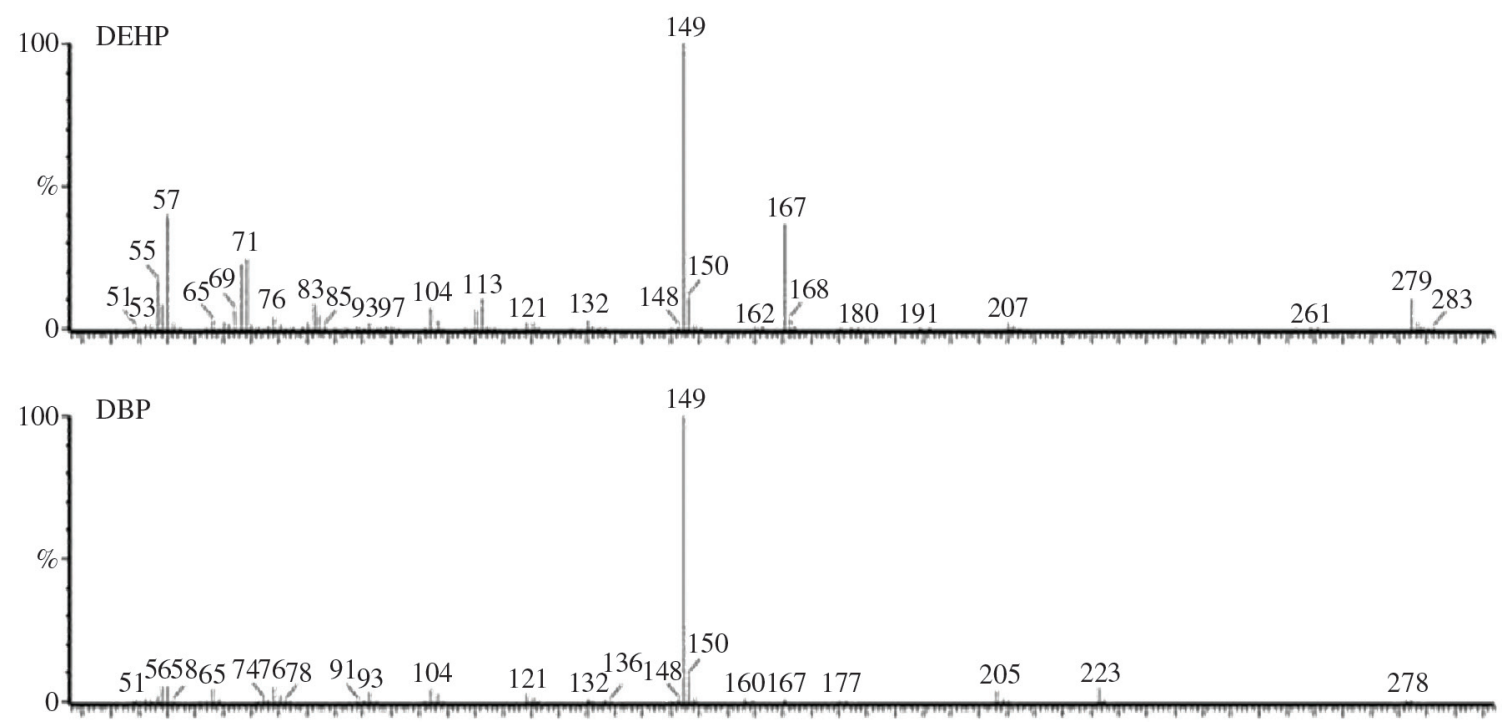

Figure 5. Comparison of spectral data for DBP and DEHP from the standard solution.
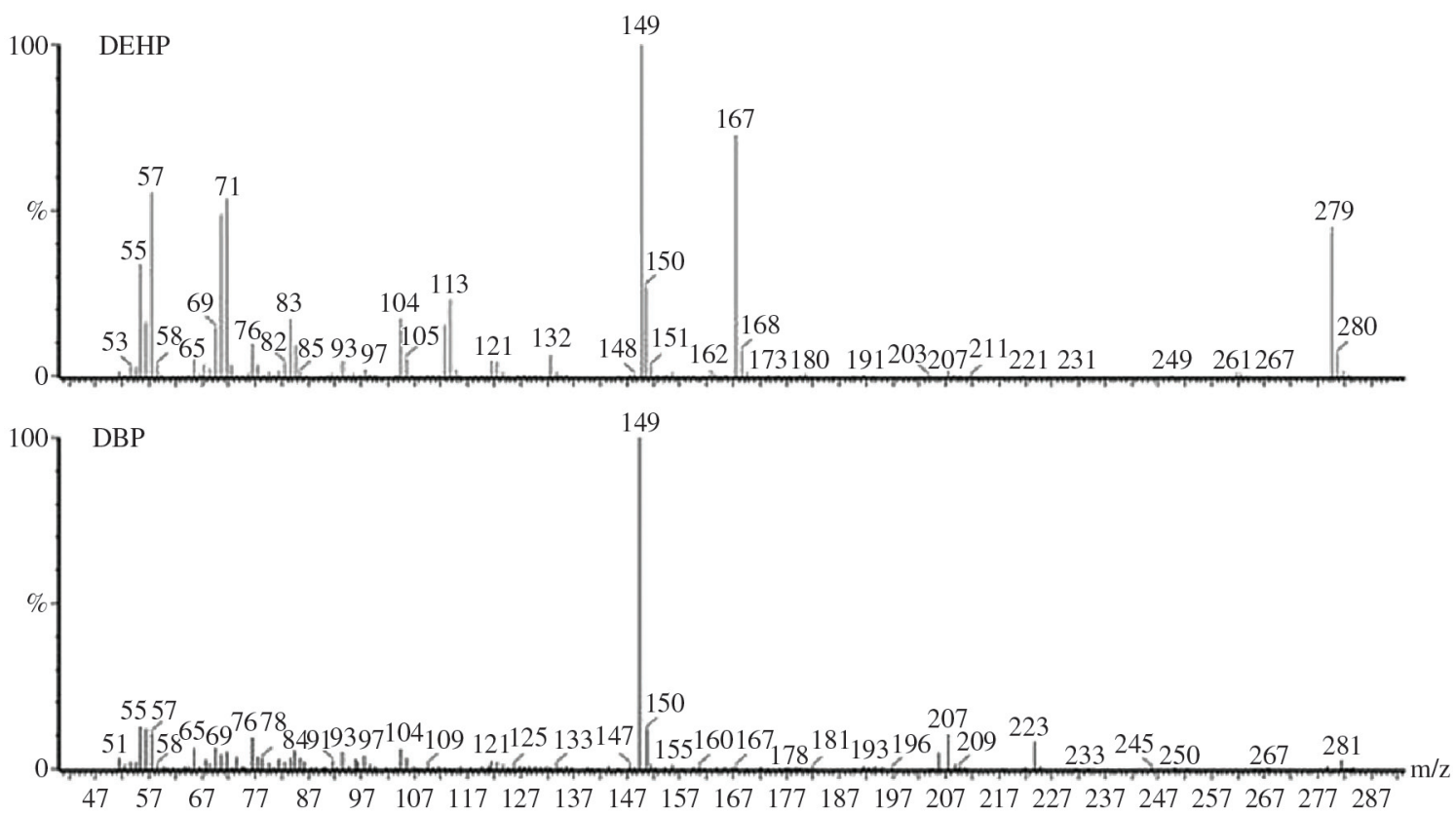

Figure 6. Comparison of spectral data for DBP and DEHP from the real sample. 
good separation of particular phthalates from polymer materials. In the method for GC/MS and GC/ECD the regression coefficient in each case was greater than 0.90 (Table 6). The chromatogram of the real sample of plasticizer obtained by GC/MS is presented in Figure 4. In Figures 5 and 6 mass spectra of DBP and DEHP from the standard and from real sample are presented for comparison.

The real samples were analyzed by GC/MS, because of the possibility of double identification of analytes by retention time and mass spectrum. The repeatability

Table 7. Repeatability of the GC/MS and GC/ECD methods for each phthalate.

\begin{tabular}{ccc}
\hline & GC/MS & GC/ECD \\
\hline Phthalate & R.S.D. $(\%)$ & R.S.D. $(\%)$ \\
\hline DMP & 0.7 & 1.8 \\
DEP & 1.3 & 1.1 \\
DBP & 0.9 & 0.8 \\
BBP & 0.7 & 0.6 \\
DEHP & 0.7 & 1.6 \\
DIOP & 1.3 & 0.5 \\
DINP & 0.4 & 1.8 \\
\hline
\end{tabular}

Table 8. Detection and quantification limits of the GC/MS and GC/ECD methods for each phthalate.

\begin{tabular}{ccccc}
\hline & \multicolumn{2}{c}{ GC/MS } & \multicolumn{2}{c}{ GC/ECD } \\
\hline Phthalate & $\mathbf{L O D}$ & $\mathbf{L O Q}$ & $\mathbf{L O D}$ & $\mathbf{L O Q}$ \\
$\left(\boldsymbol{\mu g} \mathbf{~ m L}^{-1}\right)$ & $\left(\boldsymbol{\mu} \mathbf{~ m L}^{-1}\right)$ & $\left(\mu \mathbf{~ m L}^{-1}\right)$ & $\left(\boldsymbol{\mu g ~ \mathbf { ~ L } ^ { - 1 } )}\right.$ \\
\hline DMP & 6.31 & 12.62 & 4.29 & 8.59 \\
DEP & 5.41 & 10.84 & 4.18 & 8.37 \\
DBP & 4.27 & 8.55 & 2.98 & 5.96 \\
BBP & 9.02 & 18.05 & 3.69 & 7.38 \\
DEHP & 10.10 & 20.20 & 4.01 & 8.02 \\
DIOP & 5.57 & 11.14 & 2.97 & 5.92 \\
DINP & 3.46 & 6.92 & 2.99 & 5.98 \\
\hline
\end{tabular}

of the whole analytical procedure was expressed as a relative standard deviation, and is an evaluation of the overall extraction, purification and analysis procedure. The whole process was repeated 5 times. The value of R.S.D for the GC/MS method ranged from $0.4 \%$ for DINP to $1.3 \%$ for DEP and DIOP. In case of the GC/ ECD method repeatability was in the range from $0.5 \%$ for DIOP to $1.8 \%$ for DMP and DINP (Table 7). Better repeatability was estimated for GC/MS.

The limit of detection for each phthalate was estimated as three times the value of standard deviation and the limit of quantification as five times the value of standard deviation. The values of LOD for the GC/ MS method ranged from $3.46 \mu \mathrm{g} \mathrm{mL}^{-1}$ for DINP to $10.10 \mu \mathrm{g} \mathrm{mL}^{-1}$ for DEHP, and in case of the GC/ECD method - from $2.97 \mu \mathrm{g} \mathrm{mL}^{-1}$ for DIOP to $4.29 \mu \mathrm{g} \mathrm{mL}^{-1}$ for DMP (Table 8). Application of the ECD detector, allowed reduction of the limit of quantification for all determined phthalates. The biggest LOQ differences were found in the case of DEHP.

The analyzes carried out have shown that, depending on the type of the polymeric material, total content of the phthalates determined according to the European regulations ranges from $1.7 \mathrm{mg} \mathrm{kg}^{-1}$ to $18334 \mathrm{mg} \mathrm{kg}$. The highest content of phthalates was found in samples of the plasticizer, cable and plug and it represented $1.8 \%$, $0.3 \%$ and $0.2 \%$ of polymer mass, respectively. In all the materials, except the middle part of the garden hose, and the blue coat, DEHP was detected. The concentration of DEHP ranged from $3254.1 \mathrm{mg} \mathrm{kg}^{-1}$ to $1.7 \mathrm{mg} \mathrm{kg}^{-1}$. In the case of samples obtained directly from the producers the concentration of this compound was higher than $1000 \mathrm{mg} \mathrm{kg}^{-1}$. In the case of DBP concentration in the examined materials ranged from $39.7 \mathrm{mg} \mathrm{kg}^{-1}$ to $0.9 \mathrm{mg} \mathrm{kg} \mathrm{kg}^{-1}$. The highest content of this compound, equal to $40 \mathrm{mg} \mathrm{kg}^{-1}$, was found in the black composter sample. DMP, DEP, BBP and DIOP were not found in the examined materials. The concentrations of phthalates

Table 9. Concentration of phthalates in polymer materials $\left(\mathrm{mg} \mathrm{kg}^{-1}\right)$.

\begin{tabular}{llllccccc}
\hline No. & \multicolumn{1}{c}{ Sample } & DMP & DEP & DBP & BBP & DEHP & DIOP & DINP \\
\hline 1 & Band & N.D & N.D & 28.0 & N.D & 1311.0 & N.D & N.D \\
2 & Plasticizer & N.D & N.D & 24.0 & N.D & 2110.0 & N.D & 16200 \\
3 & Cable & N.D & N.D & 7.0 & N.D & 3254.1 & N.D & N.D \\
4 & Plug & N.D & N.D & 24.3 & N.D & 2446.4 & N.D & N.D \\
5 & Garden hose & N.D & N.D & 0.9 & N.D & 178.6 & N.D & N.D \\
6 & The upper part of the garden hose & N.D & N.D & 1.5 & N.D & 267.0 & N.D & N.D \\
7 & The middle part of the garden hose & N.D & N.D & 11.0 & N.D & N.D & N.D & N.D \\
8 & Black composter & N.D & N.D & 39.7 & N.D & 160.1 & N.D & N.D \\
9 & Gray composter & N.D & N.D & 4.2 & N.D & 8.4 & N.D & N.D \\
10 & Gray container & N.D & N.D & 11.3 & N.D & 26.1 & N.D & N.D \\
11 & Black container & N.D & N.D & 5.6 & N.D & 7.6 & N.D & N.D \\
12 & Container wheel & N.D & N.D & 6.1 & N.D & 8.4 & N.D & N.D \\
13 & Green polyethylene pellets & N.D & N.D & 3.9 & N.D & 860.5 & N.D & N.D \\
14 & Black polyethylene pellets & N.D & N.D & 9.1 & N.D & 12.6 & N.D & N.D \\
15 & Polyethylene pipe & N.D & N.D & N.D & N.D & 1.7 & N.D & N.D \\
16 & Blue coat & N.D & N.D & 13.3 & N.D & N.D & N.D & N.D \\
17 & Black coat & N.D & N.D & 32.2 & N.D & 123.9 & N.D & N.D \\
\hline
\end{tabular}

N.D - not determined. 
in investigated polymer materials are shown in Table 9. In the plasticizer sample the concentrations of DEHP and DINP were higher than $0,1 \%$. Hence this material can't be used for production of polymeric materials for children and food products.

\section{Conclusion}

The method developed for the determination of phthalates in polymer materials consists of:

- Ultrasonic extraction with methylene chloride;

- Purification the extracts on silica gel column;

- Quantitative analysis on the gas chromatograph combined with mass spectrometry and on the gas chromatograph with electron capture detector.

In this paper, two methods GC/MS and GC/ECD were compared. Optimization of the extraction method was performed by determining the recoveries of the analytes using different extractants. GC/ECD method showed lower limits of detection and quantification for phthalates than the GC/MS method. Also, mass spectrometry detection was seriously disturbed by complex matrix of polymer materials, whereas ECD provided excellent phthalates profiles without interferences. However, in the case of the GC/MS method there is a possibility of double compound identification by retention time and mass spectrum. This allows determination of phthalates other than those identified in this paper.

\section{References}

1. Higuchi, T. T.; Palmer, J. S. \& Kane, C. M. - Toxicol. Sci., 72, p.301 (2003). PMid:12655036. http://dx.doi. org/10.1093/toxsci/kfg036

2. Directive of the European Parliament and of the Council 2000/60/EC. Disponível em: <http://eur-lex. europa.eu>.

3. U.S. Environmental Protection Agency. - "Technology Transfer Network Air Toxics Website: Bis(2-ethylhexyl) phthalate (DEHP)" (2000). Disponível em: <http://www. epa.gov/ttn/atw/hlthef/eth-phth.html>.

4. Directive of the European Parliament and of the Council 2005/84/EC. Disponível em: <http://eur-lex. europa.eu>.

5. Marín, M. L.; Jimenez, A.; Berenguer, V. \& Lopez, J. - J. Supercri. Fluids, 12, p.271 (1998). http://dx.doi. org/10.1016/S0896-8446(98)00086-2

6. Li, X.; Zeng, Z.; Chena, Y. \& Xu, Y. - Talanta, 63, p.1013 (2004). PMid:18969528. http://dx.doi.org/10.1016/j. talanta.2004.01.006

7. Niino, T.; Ishibashi, T.; Itho, T.; Sakai, S.; Ishiwata, H.; Yamada, T. \& Onodera, S. - J. Chromatogr. B, 780, p.35 (2002).

8. Li, X.; Zhong, M.; Xu, S. \& Sun, C. - J. Chromatogr. A, 1135, p.101 (2006). PMid:17022987. http://dx.doi. org/10.1016/j.chroma.2006.09.051
9. Ballesteros, O.; Zafra, A.; Navalon, A. \& Vilchez, J. L. - J. Chromatogr. A, 1121, p.154 (2006). PMid:16690068. http://dx.doi.org/10.1016/j.chroma.2006.04.014

10. Sablayrolles, C.; Montrejaud-Vignoles, M. \& Benanou, D. - J. Chromatogr. A, 1072, p.233 (2005). http://dx.doi. org/10.1016/j.chroma.2005.02.074

11. Cai, Y.-Q.; Jiang, G.-B.; Liu, J.-F. \& Zhou, Q.-X. - Anal. Chim. Acta, 494, p.149 (2003). http://dx.doi.org/10.1016/j. aca.2003.08.006

12. Zhao, R.-S.; Wang, X.; Yuan, J.-P. \& Lin, J.-M. - J. Chromatogr. A, 1183, p.15 (2008). PMid:18243227. http:// dx.doi.org/10.1016/j.chroma.2008.01.021

13. Liang, P.; Xu, J. \& Li, Q. - Anal. Chimi. Acta, 609, p.53 (2008). PMid:18243873. http://dx.doi.org/10.1016/j. aca.2007.12.025

14. Jen, J.-F. \& Liu, T.-Ch. - J. Chromatogr. A, 1130, p.28 (2006). PMid:16837003. http://dx.doi.org/10.1016/j. chroma.2006.06.029

15. Liang, P.; Li, Q.; Xu, J. \& Du, D. - Chromatographia, 68, p.393 (2008). http://dx.doi.org/10.1365/s10337-0080744-x

16. Lopez-Jimenez, F.J.; Rubio, S. \& Perez-Bendito, D. - Anal. Chimi. Acta, 551, p.142 (2005).

17. Jara, S.; Lysebo, C.; Greibrokk, T. \& Lundanes, E. - Anal. Chimi. Acta, 407, p.165 (2000). http://dx.doi.org/10.1016/ S0003-2670(99)00829-6

18. Ito, R.; Seshimo, F.; Miura, N.; Kawaguchi, M.; Saito, K. \& Nakazawa, H. - J. Pharma. Biomed. Analysis, 39, p.1036 (2005). PMid:16061340. http://dx.doi.org/10.1016/j. jpba.2005.06.016

19. Baker, J. K. - J. Pharma. Biomed. Analysis, 15, p.145 (1996). http://dx.doi.org/10.1016/0731-7085(96)01830-4

20. Penalver, A.; Pocurull, E.; Borrull, F. \& Marce, R. M. - J. Chromatogr. A, 872, p.191 (2000). http://dx.doi. org/10.1016/S0021-9673(99)01284-4

21. Li, J. D.; Cai, Y. Q.; Shi, Y. L.; Mou, S. F. \& Jiang, G. B. - Talanta, 74, p.498 (2008). PMid:18371667. http:// dx.doi.org/10.1016/j.talanta.2007.06.008

22. Prokupková, G.; Holadová, K.; Poustka, J. \& Hajšlová, J. - Anal. Chimi. Acta, 457, p.211 (2002).

23. Cao, X. -L. - J. Chromatogr. A, 1178, p.231 (2008). PMid:18082753. http://dx.doi.org/10.1016/j. chroma.2007.11.095

24. Bago, B.; Martin, Y.; Mejia, G.; Broto-Puig, F.; DiazFerrero, J.; Agut, M. \& Comellas, L. - Chemosphere, 59, p.1191 (2005). PMid:15833494.

25. Aparicio, I.; Santos, J. L. \& Alonso, E. - Anal. Chimi. Acta, 584, p.455 (2007). PMid:17386637. http://dx.doi. org/10.1016/j.aca.2006.11.039

26. Czaplicka, M. \& Chmielarz, A. - J. Haz. Mat., 163, p.645 (2009). PMid:18718712. http://dx.doi.org/10.1016/j. jhazmat.2008.07.010

Received: 02/22/13

Revised: 06/19/13

Accepted: 08/09/13 